\title{
Sol-gel transitions of poly(vinylidene fluoride) in organic solvents containing $\mathrm{LiBF}_{4}$
}

\author{
Hidenobu Shimizu, Yuka Arioka, Masaki Ogawa, Risei Wada and Masaru Okabe
}

Poly(vinylidene fluoride) (PVdF) dissolved in organic solvents containing lithium tetrafluoroborate $\left(\right.$ LiBF $\left._{4}\right)$ forms stable gels when the solution is cooled to room temperature. Here, we describe the effects of $\mathrm{LiBF}_{4}$ concentration and different gelation solvents on the gelation process, and characterize the resulting structural morphology using several techniques. Diethyl carbonate (DEC), propylene carbonate (PC) and $\gamma$-butyrolactone (GBL) were used as gelation solvents. Time-resolved Fourier transform infrared spectroscopic measurements showed that the conformational transition from TGT $\bar{G}$ to $T_{3} G T_{3} \bar{G}$ occurred with the addition of lithium salts to the PVdF/DEC gel. In addition, PVdF produces thermoreversible gels in GBL and PC containing LiBF 4 , by assuming a $\mathrm{T}_{3} \mathrm{GT}_{3} \overline{\mathrm{G}}$ conformation regardless of the $\mathrm{LiBF}_{4}$ concentration. Scanning electron microscopy studies have indicated the presence of spherulites in the gels. Spherulite size decreased with increasing $\mathrm{LiBF}_{4}$ concentration, whereas gel-melting temperatures increased with an increase in $\mathrm{LiBF}_{4}$ concentration. These results indicate that gelation of $\mathrm{PVdF}$ in the presence of $\mathrm{LiBF}_{4}$ occurs as polymer chains assuming the $\mathrm{T}_{3} \mathrm{GT}_{3} \overline{\mathrm{G}}$ conformation, imparting the resulting gels with increased thermal stability. Polymer Journal (2011) 43, 540-544; doi:10.1038/pj.2011.21; published online 13 April 2011

Keywords: lithium ion; molecular conformation; polymer gel electrolyte; poly(vinylidene fluoride); thermoreversible gel

\section{INTRODUCTION}

Polymer electrolytes have attracted much attention in lithium-battery technology because they enable fabrication of safe and reliable highenergy, high-power secondary lithium batteries. ${ }^{1}$ Typical examples of polymer electrolytes include complexes of a lithium salt (LiX) with PEO (polyethylene oxide). The conductivity of PEO-LiX electrolytes reaches practically useful values of $\sim 10^{-4} \mathrm{~S} \mathrm{~cm}^{-1}$ at temperatures of $60-80{ }^{\circ} \mathrm{C}$ but decreases to $10^{-7} \mathrm{~S} \mathrm{~cm}^{-1}$ at room temperature. ${ }^{2}$ Decrease in the conductivity on cooling is because fast ion transport occurs only in the amorphous state of the polymer.

The most promising approach for improving conductivity at room temperature is to immobilize a highly conductive liquid electrolyte within a polymer matrix. This type of electrolyte is called a polymer gel electrolyte. This system demonstrates high ionic conductivity at room temperature with sufficient mechanical strength., Among the matrices used for polymer gel electrolytes are $\mathrm{PVdF}^{5,6}$ poly(methyl methacrylate), ${ }^{7,8}$ and poly(acrylonitrile)..$^{9,10}$

Gel electrolytes based on PVdF are of great interest because of their good thermal, mechanical and electrochemical stability. Recent studies have shown that the ionic conductivity of PVdF gel electrolytes is related to the morphology of the gel. ${ }^{11}$ However, a detailed characterization of these gels with regard to the gelation process and structural morphology has not been undertaken. In a previous study, we reported our investigation of the gelation process of PVdF in a number of organic solvents without a lithium salt using time-resolved Fourier transform infrared (FT-IR) spectroscopy and dilatometry. ${ }^{12-15}$
In addition, we experimentally estimated the Flory-Huggins interaction parameters $\left(\chi_{12}\right)$ between PVdF and the organic solvents over a wide temperature range using inverse gas chromatography and then clarified the correlation between the thermoreversible gelation of a PVdF solution and the magnitude of $\chi_{12}{ }^{16}$

Here, we report the results of a preliminary study of the gelation process and the structural morphology of a PVdF gel in the presence of a lithium salt, $\mathrm{LiBF}_{4}$. The morphology of the PVdF gel was studied by scanning electron microscopy (SEM). The gelation process was analyzed using the measurement of gel-melting temperatures and time-resolved FT-IR.

\section{EXPERIMENTAL PROCEDURE}

Materials

A PVdF sample was kindly supplied by Kureha Corp., Tokyo, Japan and used as received. The physical properties of the sample are summarized in Table 1. The degree of crystallinity $\left(X_{\mathrm{c}}\right)$ was estimated using the following equation:

$$
X_{\mathrm{c}}[\%]=\left[\Delta H_{\mathrm{m}}^{s} / \Delta H_{\mathrm{m}}^{*}\right] \times 100
$$

where $\Delta H_{\mathrm{m}}{ }^{\mathrm{s}}$ and $\Delta H_{\mathrm{m}}{ }^{*}$ are the heats of fusion of the sample and perfectly crystalline PVdF, respectively. A Shimadzu DSC-50 heat flux differential scanning calorimeter (Shimadzu Corp., Kyoto, Japan) was used for the measurement of $\Delta H_{\mathrm{m}}$ s. The instrument was calibrated with standard indium $\left(T_{\mathrm{m}}=156.6^{\circ} \mathrm{C} ; \Delta H_{\mathrm{m}}=28.5 \mathrm{Jg} \mathrm{g}^{-1}\right)$. Differential scanning calorimeter experiments were carried out at a heating rate of $10^{\circ} \mathrm{C} \mathrm{min}^{-1}$ under a constant flow of $\mathrm{N}_{2}$ gas. In this study, $\Delta H_{\mathrm{m}}{ }^{*}$ was taken as $104.7 \mathrm{Jg}^{-1} .17$ 
Table 1 Physical properties of PVdF samples

\begin{tabular}{lccc}
\hline Sample & $\bar{M}_{W} \times 10^{-4 \mathrm{a}}$ & $T_{m}\left({ }^{\mathrm{o} C}\right)^{\mathrm{b}}$ & $X_{c}(\%)^{\mathrm{c}}$ \\
\hline $\mathrm{PVdF}$ & 42.7 & 177.2 & 59.9
\end{tabular}

Abbreviation: PVdF, poly(vinylidene fluoride)

aviscosity average molecular weight was determined by intrinsic viscosity in $N, N^{\prime}$-dimethyl-

acetamide (DMA) at $25^{\circ} \mathrm{C}$ using the following equation: $[\eta]=2.01 \times 10^{-4} \overline{\mathrm{M}}_{\mathrm{W}}{ }^{0.675}$

bMelting temperature was measured by differential scanning calorimeter (DSC).

'Degree of crystallinity was estimated from DSC using Equation (1).

Diethyl carbonate (DEC), propylene carbonate (PC), and $\gamma$-butyrolactone (GBL) (special-grade reagent from Kanto Chemical, Co., Inc., Tokyo, Japan) were used as gelation solvents. These solvents were dried over Molecular Sieves $4 \mathrm{~A}$ for 1 week and then distilled under reduced pressure before use. $\mathrm{LiBF}_{4}$ was purchased from Kanto Chemical and used without further purification.

\section{Swelling ratio}

The equilibrium swelling properties of PVdF films were measured gravimetrically at $60^{\circ} \mathrm{C}$. PVdF films were prepared using hot pressing of $\mathrm{PVdF}$ powder, followed by $\gamma$-ray irradiation. The preweighed dry PVdF films were immersed in a large excess of organic solvent at $60^{\circ} \mathrm{C}$ until equilibrium was reached. The wet films were then removed from the solvent, blotted quickly and reweighed. The swelling ratios $(Q)$ of the films were determined as:

$$
Q=\left(W_{\mathrm{s}}-W_{\mathrm{d}}\right) / W_{\mathrm{d}}
$$

where $W_{\mathrm{s}}$ and $W_{\mathrm{d}}$ are the weights of the swollen and dried films, respectively.

\section{Gel-melting temperatures}

It is well known that the gel-melting temperature $\left(T_{\mathrm{m}} \mathrm{g}\right)$ of crystalline polymer does not coincide with the temperature at which the last trace of crystallites has melted away. ${ }^{18}$ In a sol, large numbers of crystallites still exist. Consequently, measurement of gel-melting temperature using differential scanning calorimeter is inadequate. In this study, gel-melting temperatures were measured by the falling-ball method. ${ }^{19}$ A prescribed amount of PVdF and gelation solvent was placed in an 8-mm-diameter glass tube, and the tube was sealed. The mixtures were homogenized at $170{ }^{\circ} \mathrm{C}$, and then the glass tube was placed in a water bath held at $30^{\circ} \mathrm{C}$ to prepare a gel. A 2-mm-diameter steel ball weighing $\sim 30 \mathrm{mg}$ was placed on top of the gel. The gel was then heated at the rate of $\sim 0.3^{\circ} \mathrm{C} \mathrm{min}{ }^{-1}$, and the height of the steel ball was measured from a reference level as a function of temperature using a cathetometer. When the gel melted, that is, was converted to sol, the steel ball began to move downward. The gelmelting temperature was determined by the method of Takahashi et al. ${ }^{19}$

\section{FT-IR spectroscopy}

Time-resolved FT-IR measurements were performed using a JASCO FT-IR spectrometer, Model FT/IR-660 (JASCO, Tokyo, Japan). The PVdF powder was first completely dissolved in the gelation solvent at a concentration of $10 \mathrm{wt} \%$, and then the solution was rapidly poured into a KRS- 5 cell and placed in the FT-IR spectrometer. The FT-IR spectra were recorded by the attenuated total reflection method at intervals of $10 \mathrm{~s}$ with a wavelength resolution of $4 \mathrm{~cm}^{-1}$. The spectra were obtained by subtracting the spectra of the pure solvent from those of PVdF gel.

\section{Morphology}

Gel morphology was investigated with SEM. PVdF gels were prepared in a sealed glass tube as described above. A small portion of these gels were then taken out and dried under vacuum. SEM was carried out on a SSX-550 scanning electron microscope (Shimadzu), and surfaces of the gels were analyzed under vacuum after gold was sputtered onto the gels.

\section{RESULTS AND DISCUSSION}

\section{Swelling ratios in liquid organic electrolytes}

Cross-linked PVdF films were allowed to swell in different organic solvents with or without $\mathrm{LiBF}_{4}$ until equilibrium was reached at $60^{\circ} \mathrm{C}$,

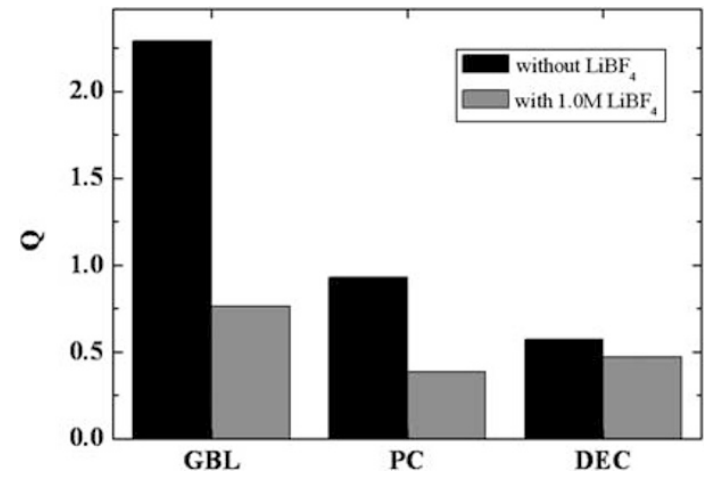

Figure 1 Weight swelling ratios $(Q)$ of $P V d F$ films in various organic solvents with and without $1.0 \mathrm{~m} \mathrm{LiBF}_{4}$.

and then the swelling ratios of the PVdF films were measured gravimetrically. The results are shown in Figure 1. The concentration of $\mathrm{LiBF}_{4}$ was $1.0 \mathrm{M}$. In the absence of the lithium salt, the swelling ratios were strongly affected by the gelation solvent used, and the ratios increased in the following order: $\mathrm{DEC}<\mathrm{PC}<\mathrm{GBL}$. This order can be explained by solubility parameters of the solvents and the polymer. The solubility parameters of DEC, PC and GBL are 18.0, 27.2 and 25.8 $\left(\mathrm{MPa}^{1 / 2}\right)$, respectively. ${ }^{20}$ According to Bottino et al., ${ }^{21} \mathrm{PVdF}$ has a solubility parameter of $23.2\left(\mathrm{MPa}^{1 / 2}\right)$. The swelling ratios tended to increase as the solubility parameters for the solvent and PVdF were closer, that is, as the polymer becomes more soluble in the solvent.

Figure 1 also shows that the addition of the lithium salt to the gelation solvent decreased the swelling ratios for all solvents. PVdF chains have a low affinity for lithium salts; ${ }^{22}$ thus, the decrease in the swelling ratios upon the addition of the lithium salt may be due to a difference in osmotic pressure inside and outside the PVdF film.

\section{Infrared spectral analysis}

Poly(vinylidene fluoride) has at least four different polymorphs, designated $\alpha, \beta, \gamma$ and $\delta .{ }^{23}$ The $\alpha$ - and $\gamma$-forms have TGTG (shortperiod) and $\mathrm{T}_{3} \mathrm{GT}_{3} \overline{\mathrm{G}}$ (long-period) helical conformations, respectively. The $\beta$-form has an all-trans conformation, and the $\delta$-form is a polar analog of the $\alpha$-form. We investigated the effect of gelation conditions such as the gelation solvent used and $\mathrm{LiBF}_{4}$ concentrations on the conformation of PVdF chains in the gels using FT-IR, which has emerged as a powerful tool to investigate the conformations of various polymorphs of PVdF.

Figure 2 presents the $450-650 \mathrm{~cm}^{-1}$ region of the FT-IR spectra of $\mathrm{PVdF} /$ organic solvent systems as a function of $\mathrm{LiBF}_{4}$ concentrations. DEC (Figure 2a), PC (Figure 2b) and GBL (Figure 2c) were used as gelation solvents. The $450-650 \mathrm{~cm}^{-1}$ region is highly sensitive to conformational changes of PVdF chains. ${ }^{24}$ As shown in Figure 2a1, the absorption bands near 615,532 and $491 \mathrm{~cm}^{-1}$ appeared with time in the PVdF/DEC gel without $\mathrm{LiBF}_{4}$. These bands are characteristic of TGTG conformation, and it is thus evident that the TGT $\bar{G}$ conformation is associated with macroscopic gelation. The addition of $0.5 \mathrm{M} \mathrm{LiBF}_{4}$ yielded new vibrational bands at 511 and $484 \mathrm{~cm}^{-1}$. These bands are associated with the $\mathrm{T}_{3} \mathrm{GT}_{3} \overline{\mathrm{G}}$ conformation, indicating that PVdF chains in DEC containing $0.5 \mathrm{M} \mathrm{LiBF}_{4}$ display a mixture of both the TGTG and the $\mathrm{T}_{3} \mathrm{GT}_{3} \overline{\mathrm{G}}$ conformations. Increasing the concentration of $\mathrm{LiBF}_{4}$ up to $1.0 \mathrm{M}$ resulted in gelation with only the $\mathrm{T}_{3} \mathrm{GT}_{3} \overline{\mathrm{G}}$ conformation. These results suggest that a conformational transition from TGT $\bar{G}$ to $\mathrm{T}_{3} \mathrm{GT}_{3} \overline{\mathrm{G}}$ occurs upon the addition of lithium salts to a PVdF/DEC gel system. 


\section{a}

without $\mathrm{LiBF}_{4}$

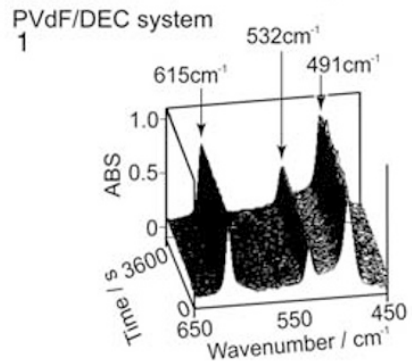

b $\mathrm{PVdF} / \mathrm{PC}$ system

1

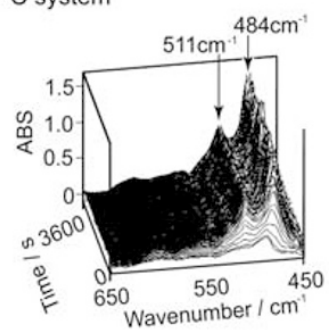

C $\mathrm{PVdF} / \mathrm{GBL}$ system

1

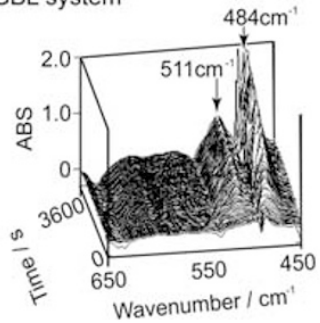

with $0.5 \mathrm{M} \mathrm{LiBF}_{4}$

2

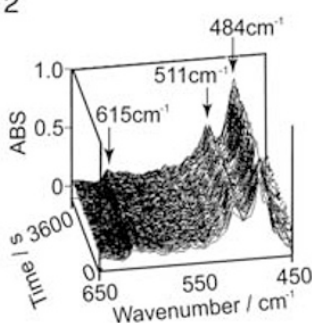

2

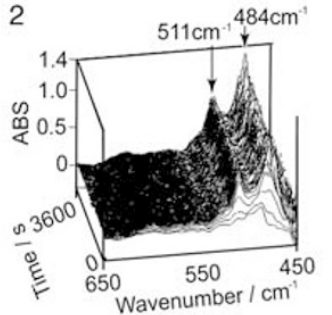

2

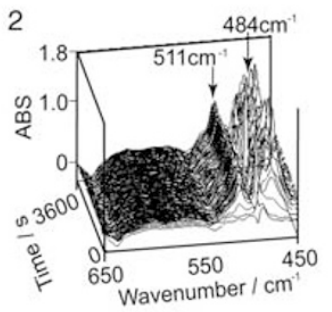

with 1.0M $\mathrm{LiBF}_{4}$
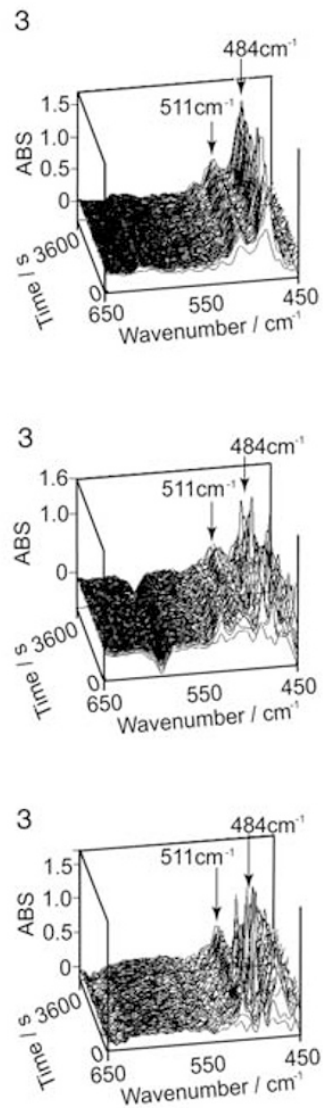

Figure 2 Time-resolved FT-IR spectra of PVdF/organic solvent systems containing various concentrations of $\mathrm{LiBF}_{4}$.

Figures $2 \mathrm{~b}$ and $\mathrm{c}$ show that all of the spectra have absorption bands near 511 and $484 \mathrm{~cm}^{-1}$; these bands are associated with the $\gamma$-polymorph of PVdF chains. These results indicate that the presence of lithium salts had no influence on the conformation of PVdF chains in PC and GBL.

As shown in Figures 2a3, b3 and c3, the same vibrational bands near 511 and $484 \mathrm{~cm}^{-1}$ were observed in PVdF gels with $1.0 \mathrm{M} \mathrm{LiBF}_{4}$. These bands are characteristic of the long-period conformation $\mathrm{T}_{3} \mathrm{GT}_{3} \overline{\mathrm{G}}$ (the TT and TGTG have also been observed in PVdF). These results suggest that PVdF chains tend to take a long-period conformation in the presence of lithium salts. The formation of shortperiod conformation may be inhibited due to complex formation by the PVdF chains and solvated lithium ions.

Figure 2 provides valuable information about not only the molecular conformation in PVdF gels but also the kinetics of gel formation. However, in the presence of lithium salts, gelation tends to take only 2 or $3 \mathrm{~min}$; thus, we mainly determined the molecular structure of the PVdF gel from the IR spectra.

\section{Gel-melting temperature}

Figure 3 shows the relation between gel-melting temperatures $\left(T_{\mathrm{m}}{ }^{\mathrm{g}}\right)$ and polymer concentrations at varying $\mathrm{LiBF}_{4}$ concentrations. Gelmelting temperatures increased gradually with an increase in polymer concentration and also strongly depended on the gelation conditions such as the gelation solvent used and $\mathrm{LiBF}_{4}$ concentration. At the same concentration of $\mathrm{LiBF}_{4}, T_{\mathrm{m}}{ }^{\mathrm{g}}$ increased in the following order:

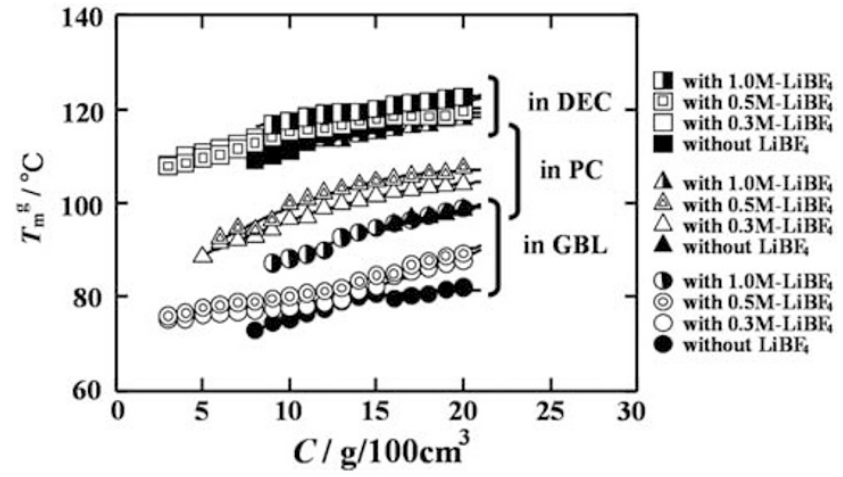

Figure 3 Relationship between gel-melting temperatures $\left(T_{\mathrm{m}} \mathrm{g}\right)$ and polymer concentrations $(C)$ with varying $\mathrm{LiBF}_{4}$ concentrations and gelation solvents.

$\mathrm{PVdF} / \mathrm{GBL}$ gel $<\mathrm{PVdF} / \mathrm{PC}$ gel $<\mathrm{PVdF} / \mathrm{DEC}$ gel. As illustrated in Figure 1, the swelling ratios in the absence of $\mathrm{LiBF}_{4}$ decreased in this order. We concluded from these results that $T_{\mathrm{m}}{ }^{\mathrm{g}}$ tends to increase with a decrease in swelling ratios. A large difference in solubility parameters between PVdF and the gelation solvent would result in decreased swelling ratios, leading to an increase in $T_{\mathrm{m}}{ }^{\mathrm{g}}$. We previously reported that the $T_{\mathrm{m}}{ }^{\mathrm{g}}$ values of PVdF gels in the absence of lithium salts ${ }^{16}$ and those of poly(butylene succinate) gels $^{25}$ increase with an increase in the polymer-solvent interaction parameter. 


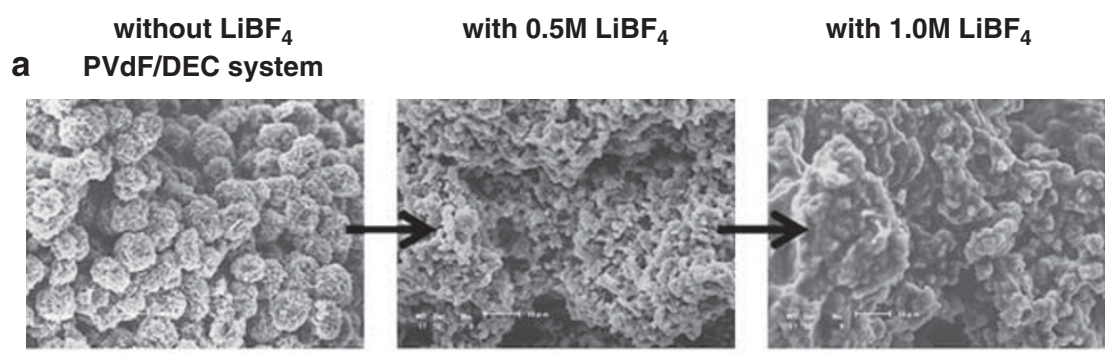

\section{b PVdF/PC system}

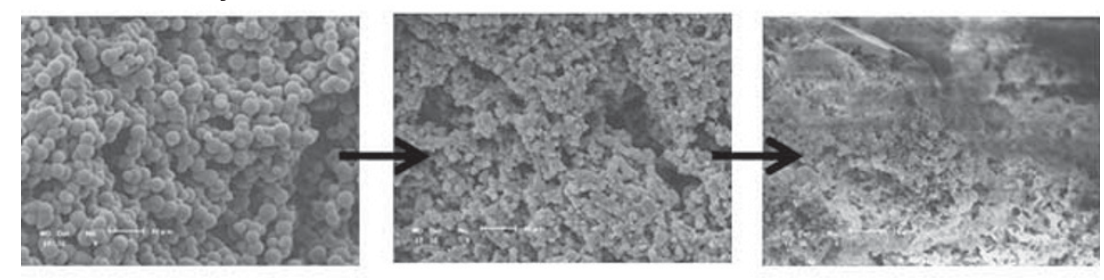

\section{PVdF/GBL system}

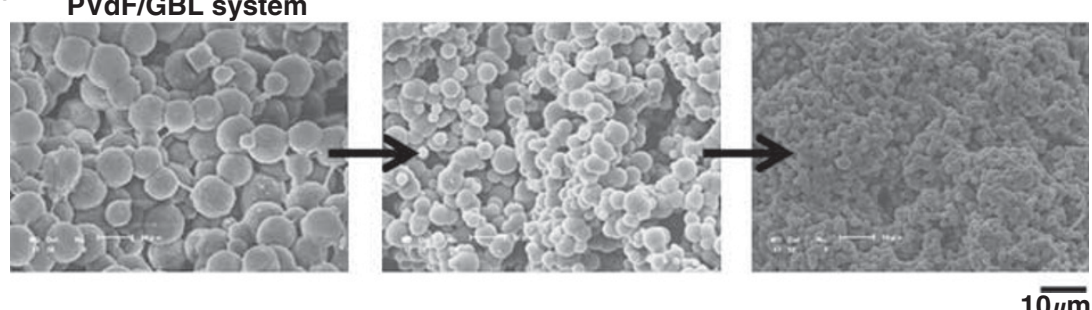

$\overline{10 \mu \mathrm{m}}$

Figure 4 SEM images of dried PVdF gels produced in various organic solvents at varying $\mathrm{LiBF}_{4}$ concentrations.

Figure 3 also shows that $T_{\mathrm{m}} \mathrm{g}$ increased with an increase in $\mathrm{LiBF}_{4}$ concentration in the same solvent. These results indicate that the addition of the lithium salt led to increased thermal stability in PVdF gels. The thermal stability of a physical gel generally increases with an increase in junction density and size. According to the Tanaka and Stockmayer ${ }^{26}$ as well as Tanaka and Nishinari ${ }^{27}$ theory, the junction points of a physical gel are aggregates composed of $\zeta$ units in length and $\rho$ sequences in cross-section. PVdF chains have a low affinity for lithium salts; individual PVdF chains may readily aggregate in a lithium salt-containing solvent. In addition, the inhibition of crystallization due to complex formation may promote entanglements among the PVdF chains. As a result, various factors could influence the thermal stability of PVdF gels with lithium salts.

\section{Morphology}

Figure 4 presents SEM images of dried PVdF gels produced in organic solvents with different concentrations of $\mathrm{LiBF}_{4}$. The polymer concentration was $6 \mathrm{wt} \%$. As shown in Figure 4, well-developed spherulites, which are spherical aggregates of lamellar crystallites, were observed regardless of the gelation conditions. These results indicate that the formation of a three-dimensional network structure was caused by the aggregation of spherulites. Conversely, the gelation conditions had a strong influence on the size and morphology of the spherulites obtained. In the PVdF/DEC system (Figure 4a), the spherulites had a rough surface, whereas the surface of the spherulites was smooth when using GBL or PC as the gelation solvent. We estimated from Figure 4 that the spherulites are $\sim 10 \mu \mathrm{m}$ in diameter in PVdF gels made without $\mathrm{LiBF}_{4}$, whereas the size was reduced to $\sim 2.0 \mu \mathrm{m}$ with increasing $\mathrm{LiBF}_{4}$ concentrations. Complex formation by PVdF chains and solvated lithium ions may prevent the crystallization process, resulting in the formation of smaller spherulites.

\section{Conclusions}

The results of this study revealed the following for the gelation of $\mathrm{PVdF}$ in organic solvents containing $\mathrm{LiBF}_{4}$ :

1. Gelation in the presence of a lithium salt occurs as the PVdF chains assume the $\mathrm{T}_{3} \mathrm{GT}_{3} \overline{\mathrm{G}}$ conformation.

2. The addition of a lithium salt increases the gel-melting temperature, resulting in improved thermal stability of the polymer gel electrolyte.

3. From SEM measurements, spherulitic growth was observed, and the spherulites became smaller with increasing $\mathrm{LiBF}_{4}$ concentration.

4. Investigation of the fundamental characteristics of the gelation of PVdF in the presence of lithium salts may facilitate the development of polymer gel electrolytes for secondary lithium batteries.

1 Dias, F. B., Plomp, L. \& Veldhuis, J. B. J. Trends in polymer electrolytes for secondary lithium batteries. J. Power Sources 88, 169-191 (2000).

2 Croce, F., Appetecchi, G. B., Persi, L. \& Scrosati, B. Nanocomposite polymer electrolytes for lithium batteries. Nature 394, 456-458 (1998).

3 Abraham, K. M. \& Alamgir, M. Li+-conductive solid polymer electrolytes with liquid-like conductivity. J. Electrochem. Soc. 137, 1657-1658 (1990).

4 Saikia, D. \& Kumar, A. Ionic conduction in P(VDF-HFP)/PVDF-(PC + DEC) $-\mathrm{LiClO}_{4}$ polymer gel electrolytes. Electrochimica. Acta. 49, 2581-2589 (2004).

5 Bansal, D., Cassel, F., Croce, F., Hendrickson, M., Plichta, E. \& Salomon, M. Conductivities and transport properties of gelled electrolytes with and without an ionic liquid for Li and Li-ion bateries. J. Phys. Chem. B 109, 4492-4496 (2005). 
6 Saito, Y., Kataoka, H., Quartarone, E. \& Mustarelli, P. Carrier migration mechanism of physically cross-linked polymer gel electrolytes based on PVDF membranes. J. Phys. Chem. B 106, 7200-7204 (2002).

7 Osaka, T., Momma, T., Ito, H. \& Scrosati, B. Performances of lithium/gel electrolyte/ polypyrole secondary batteries. J. Power Sources 68, 392-396 (1997).

8 Adebahr, J., Forsyth, M., Gavelin, P., Jacobsson, P. \& Oradd, G. Ion and solvent dynamics in gel electrolytes based on ethylene oxide grafted acrylate polymers. J. Phys. Chem. B 106, 12119-12123 (2002).

9 Croce, F., Gerace, F., Dautzemberg, G., Passerini, S., Appetecchi, G. B. \& Scrosati, B. Synthesis and characterization of highly conducting gel electrolytes. Electrochim. Acta. 39, 2187-2194 (1994).

10 Nicotera, I., Oliviero, C., Ranieri, G., Spadafora, A., Castriota, M. \& Cazzanelli, E. Temperature evolution of thermoreversible polymer gel electrolytes $\mathrm{LiClO}_{4}$ /ethylene carbonate/poly(acrylonitrile). J. Chem. Phys. 117, 7373-7380 (2002).

11 Saito, Y., Kataoka, H. \& Stephan, A. M. Investigation of the conduction mechanisms of lithium gel polymer electrolytes based on electrical conductivity and diffusion coefficient using NMR. Macromolecules 34, 6955-6958 (2001).

12 Tazaki, M., Wada, R., Okabe, M. \& Homma, T. Crystallization and gelation of poly (vinylidene fluoride) in organic solvents. J. Appl. Polym. Sci. 65, 1517-1524 (1997).

13 Sato, Y., Wada, R., Tazaki, M. \& Okabe, M. Gelation process of poly(vinylidene fluoride) in cyclohexanone. Nippon Kagaku Kaishi 481-488 (1998).

14 Wada, R., Sato, Y., Tazaki, M. \& Okabe, M. Sol-gel transition of poly(1,1,-difluoroethylene) in $\gamma$-butyrolactone/cyclohexanone mixed solvent. Nippon Kagaku Kaishi 253-259 (1999).

15 Wada, R., Aihara, K., Nomoto, H., Tazaki, M. \& Okabe, M. Sol-gel transition curve of poly(vinylidene fluoride) in organic solvents. Nippon Kagaku Kaishi 797-802 (2000).

16 Okabe, M., Wada, R., Tazaki, M. \& Homma, T. The Flory-Huggins interaction and thermoreversible gelation of poly(vinlyidene fluoride) in organic solvents. Polym. J. 35, 798-803 (2003).
17 Rosenberg, Y., Siegmann, A., Narkis, M. \& Shkolnik, S. The sol/gel contribution to the behavior of $\gamma$-irradiated poly(vinylidene fluoride). J. Appl. Polym. Sci. 43, 535-541 (1991).

18 Mitsui, K. \& Okabe, M. Gel-melting process of linear high-density polyethylene-decalin gel prepared at various cooling rates and gel-melting temperature by Falling-Ball method. Nippon Kagaku Kaishi 136-143 (1995).

19 Takahashi, A., Sakai, M. \& Kato, T. Melting temperature of thermally reversible gel. VI. Effect of branching on the sol-gel transition of polyethylene gels. Polym. J. 12, 335-341 (1980).

20 Brandrup, J., Immergut, E. H. \& Grulke, E. A. (eds). Polymer Handbook, 4th edn, pVII-689-693 (John Wiley \& Sons: New York, 1999).

21 Bottino, A., Capannelli, G., Munarai, S. \& Turturro, A. Solubility parameters of poly(vinylidene fluoride). J. Polym. Sci. B, Polym. Phys. 26, 785-794 (1988).

22 Saunier, J., Alloin, F., Sanchez, J. Y. \& Barriere, B. Plasticized microporous poly (vinylidene fluoride) separators for lithium-ion batteries. I. Swelling behavior of dense membranes with respect to a liquid electrolyte-characterization of the swelling equilibrium. J. Polym. Sci. B, Polym. Phys. 42, 532-543 (2004).

23 Tashiro, K. Ferroelectric Polymers: Chemistry, Physics, and Applications (ed. Nalwa, H. S.) 63-181 (Marcel Dekker: New York, NY, 1995).

24 Benedetti, E., D’Alessio, A., Bertolutti, C., Vergamini, P., Fanti, N. D., Pianca, M. \& Moggi, G. Influence of molecular weight on the crystallization of poly(vinylidene fluoride). Polym. Bull. 22, 645-651 (1989).

25 Takigawa, Y., Ohsato, H., Mihirogi, S., Wada, R., Imaizumi, M., Shimizu, H. \& Okabe, M. Sol-gel transition of poly (butylene succinate) in organic solvents. Kobunshi Ronbunshu 61, 184-189 (2004).

26 Tanaka, F. \& Stockmayer, W. H. Thermoreversible gelation with junctions of variable multiplicity. Macromolecules 27, 3943-3954 (1994).

27 Tanaka, F. \& Nishinari, K. Junction multiplicity in thermoreversible gelation. Macromolecules 29, 3925-3928 (1996). 